\title{
About Fluence and Process Parameters on Maraging Steel Processed by Selective Laser Melting: Do They Convey the Same Information?
}

\author{
Stefania Cacace ${ }^{1, \#}$ and Quirico Semeraro' \\ 1 Department of Mechanical Engineering, Politecnico di Milano, Via La Masa 1, 20156 Milan, Italy \\ \# Corresponding Author / E-mail: stefania.cacace@polimi.it. TEL: +39 0223998592 \\ ORCID: 0000-0003-2121-6276
}

KEYWORDS: Additive manufacturing, Design and analysis of experiments, Optimal alphabetical designs, Tool steel

\begin{abstract}
In this paper the influence of process parameters and fluence on mechanical properties of maraging steel in Selective Laser Melting (SLM) is studied. The results of the present work show that there exists a steady region of process parameters where fluence conveys all the information required to describe and predict density and tensile properties. We also show that in this region of the parameters, the choice of process parameters can be carried out considering other optimality criteria such as productivity, rather than maximization of density. To pursue this objective, a V-Alphabetical optimal design with fixed fluence levels was specifically designed for the experimentation. The used fluence levels and the corresponding process parameter combinations were tested on an industrial SLM system. To compare the informative content of fluence and the process parameters, two regression equation were estimated from experimental results for part density and tensile properties. The comparison of the regression models showed that the predictive ability of fluence and process parameters in the steady region is the same, however fluence allowed to obtain a higher precision. In conclusion, based on the experimental conditions studied, new process parameters are suggested using a productivity-based criteria.
\end{abstract}

Manuscript received: March 22, 2018 / Revised: September 25, 2018 / Accepted: September 27, 2018 This article is published with open access at Springerlink.com

\section{Introduction}

Metal Additive Manufacturing (AM) is a new manufacturing method that gained attention in the last years. Compared to the traditional machining processes, the material is added layer by layer to produce the final part. The popularity of AM is due to the possibility to exploit freeform design to produce parts with complex geometries and inner geometrical features that could not be achieved with traditional processes. Other advantages of AM are short lead times and high customization. For these reasons, AM became popular in different industry sectors such as aerospace, bio-medical industries and tooling. However, the adoption of AM by a wider number of industries is limited by several drawbacks of the technology, for example: low process productivity, high production costs, low availability of alloys and lack of sound process experience.

Most of the current metal AM systems are based on the Powder Bed Fusion (PBF) technology. ${ }^{1}$ The most common PBF processes are Selective Laser Melting (SLM) and Electron Beam Melting (EBM).
The main difference between the two processes is the medium used to melt the material: the former uses a laser source and the latter an electron beam source. In this paper, the focus will be on the Selective Laser Melting process.

The SLM process starts from a thin powder layer spread upon a building plate, the laser beam selectively melts the powder using CAD data as input. When the layer is completed, the plate is lowered and the process is repeated until the part is built.

The mechanical properties of the final part depend on the process parameters. Some studies showed that the part density and the associated average porosity depend on a few process parameters. ${ }^{2-5}$

These parameters define the amount of energy delivered by the laser to the powder bed. Industrial machines can be equipped with continuous or pulsed lasers. For continuous lasers, the energy is delivered to the material continuously in time, therefore the interaction between the beam and the material depends, among other parameters, on the speed of the laser. In pulsed mode lasers, the energy is delivered in precise point in space and for a defined amount of time (exposure time). In this 


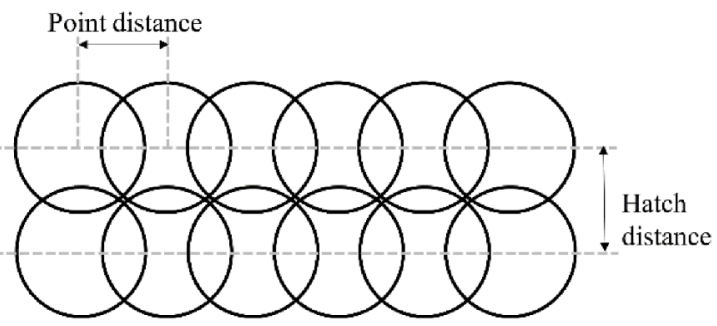

Fig. 1 Graphical representation of point distance and hatch distance
Part density and tensile properties are measured and statistically analyzed to verify if they depend on the individual values of the process parameters used or, only, on the synthetic value of fluence.

The paper is organized as follows. In Section 2 the problem is discussed in detail. In Section 3 reports the experimental set up, materials and methods used. In Section 4 the results of the density and tensile property measurements are discussed. Eventually some hints about the process parameters setting to improve the process productivity is given. In Appendix A the algorithm used for the generation of the processing condition is described in detail.

second case, the beam-material interaction depends on the distance between consecutive points (point distance and hatch distance) and the exposure time. A graphical representation of point distance and hatch distance is reported in Fig. 1. From now on, we will focus on pulsed laser as our experimentation was performed on a Renishaw industrial machine equipped with a pulsed laser.

The application of pulsed emission laser in the selective laser melting process is gaining attention in the last years. ${ }^{6}$ Pulsed laser allows a major control on the melt pool dimension and on the thermal interaction between the laser and the powder. ${ }^{7}$ As a result, the production of components with small dimensions is favored. The advantages and drawbacks of pulsed laser in SLM can be found in works by Demir et al. ${ }^{6}$ and Kaden et al.. ${ }^{7}$ In literature different applications of pulsed laser in SLM are available. For example, the failure behavior of Al-Si10-Mg lattice structures produced with Renishaw AM250 was studied. ${ }^{8}$ The same industrial machine and material were used to study the mechanical properties of different honeycomb structures. ${ }^{9}$ Different materials have been processed using pulsed mode obtaining good results in terms of density and mechanical properties. Copper samples and thin wall structures were produced using a pulsed SLM system. ${ }^{7}$ Renishaw AM250 is a pulsed-laser SLM system which was used to produce parts with different geometries and materials, here we report some examples of applications. Near net-shape cardiovascular stents were fabricated with $\mathrm{CoCr}$ powder. ${ }^{10}$ Stainless steel $316 \mathrm{~L}$ test cubes were produced obtaining a porosity lower than $0.5 \%{ }^{11}$ Ti-6Al- $4 \mathrm{~V}$ was used to study the influence of particle size distribution on SLM process; the achieved final part density was close to $100 \% .^{12}$

In literature, several papers, both for continuous and pulsed lasers, ${ }^{6,13-17}$ show that density depends on the energy density also known as fluence. Fluence is an important index since it unifies several process parameters in just one parameter. However, we were not able to find a paper proving with a statistical sound method that fluence can be used to predict the mechanical properties regardless the specific process parameters.

The goal of this paper is to prove that in a steady process region, it is possible to replace the specific process parameters with the fluence index as the unique parameter to predict the mechanical part properties. If this were proven true, the user could choose the process parameters to improve the process speed which is the main SLM production problem.

To experimentally prove this statement, different fluence levels belonging to a steady process region are tested, and different combinations of specific process parameters (from now on, these combinations will be called treatments) are used for each fluence level.

\section{Problem Statement}

Fluence is defined as the amount of energy delivered to the powder bed by the laser. For pulsed lasers, the definition of fluence: ${ }^{6,11}$

$$
F=100 \frac{t \cdot P}{d_{p} \cdot d_{h}}
$$

where $P$ is the power of the laser [W], $t$ is the exposure time [ $\mu \mathrm{s}], d_{p}$ is the point distance $[\mu \mathrm{m}]$ and $d_{h}$ is the hatch distance $[\mu \mathrm{m}]$. Eq. (1) is multiplied by a scaling factor of 100 to obtain fluence in $\left[\mathrm{J} / \mathrm{cm}^{2}\right]$.

Fluence can be defined also considering the layer thickness used during the process. In this case the equation for fluence is changed by dividing it by the layer thickness, thus obtaining a volumetric density $\left[\mathrm{J} / \mathrm{cm}^{3}\right]$. In the experiment carried out for this work, layer thickness was not varied and therefore we refer to fluence as an energy surface index.

The energy delivered by the laser to the powder allows to melt the powder and to build a dense layer of material. For this reason, fluence has been studied, above all, in relation to the final part density.

As a matter of fact, the fluence should be enough to melt the powder layer but also to re-melt the previous layer to increase bonding between successive layers and avoid the formation of defects. ${ }^{18}$

On the other side, if the fluence is too high, vaporization might occur in the layer causing the formation of defects. ${ }^{3}$ Other important factors affecting mechanical properties have been reported, such as scanning strategies, ${ }^{3}$ spot size, ${ }^{19}$ part orientation and location ${ }^{20}$ and powder properties, ${ }^{21}$ but they are out of scope of the present paper. As previously discussed, many papers in literature use fluence as an effective factor to describe the mechanical properties of AM parts, however there are few available studies ${ }^{22-24}$ showing the advantage of using fluence as a unique parameter instead of its components i.e. laser power, hatch distance, point distance and exposure time for pulsedmode laser and laser power or scan speed and hatch distance for continuous lasers. Gu et al. ${ }^{22}$ made experiments in SLM-Continuous mode using 17-4PH stainless steel. One level of fluence was considered and only two process parameters were varied, i.e. laser power and scan speed while hatch distance was held constant. Six different treatments (combination of parameters), without replicates, resulting in the same level of fluence were used to perform the study. The results showed that if process parameters are chosen at extreme values (very high/low value) the final part density resulted compromised. However, this research focused on one level of fluence and the experiment was made with a continuous mode laser.

Prashanth et al. ${ }^{23}$ studied the influence of fluence on AL-12Si with 
Table 1 Summary on the state of the art for fluence in selective laser melting process

\begin{tabular}{|c|c|c|c|c|c|}
\hline Paper & $\begin{array}{l}\text { \# Fluence levels } \\
\text { and values }\end{array}$ & Laser type & Material & $\begin{array}{c}\text { Process } \\
\text { parameters varied }\end{array}$ & Measured response \\
\hline Gu et al. ${ }^{22}$ & $1\left(61 \mathrm{~J} / \mathrm{mm}^{3}\right)$ & Continuous & 17-4PH & Powers, scan speed & Density, grain size, phase proportion \\
\hline Prashanth et al. ${ }^{23}$ & $1\left(55 \mathrm{~J} / \mathrm{cm}^{3}\right)$ & Continuous & Al-Si12Mg & Power, scan speed & Tensile properties, density \\
\hline Scipioni Bertoli et al. ${ }^{24}$ & $6\left(48-242 \mathrm{~J} / \mathrm{mm}^{3}\right)$ & Continuous & AISI 316L & Power, scan speed & Track morphology (width, height, depth) \\
\hline
\end{tabular}

Table 2 Optimal points for the V-design

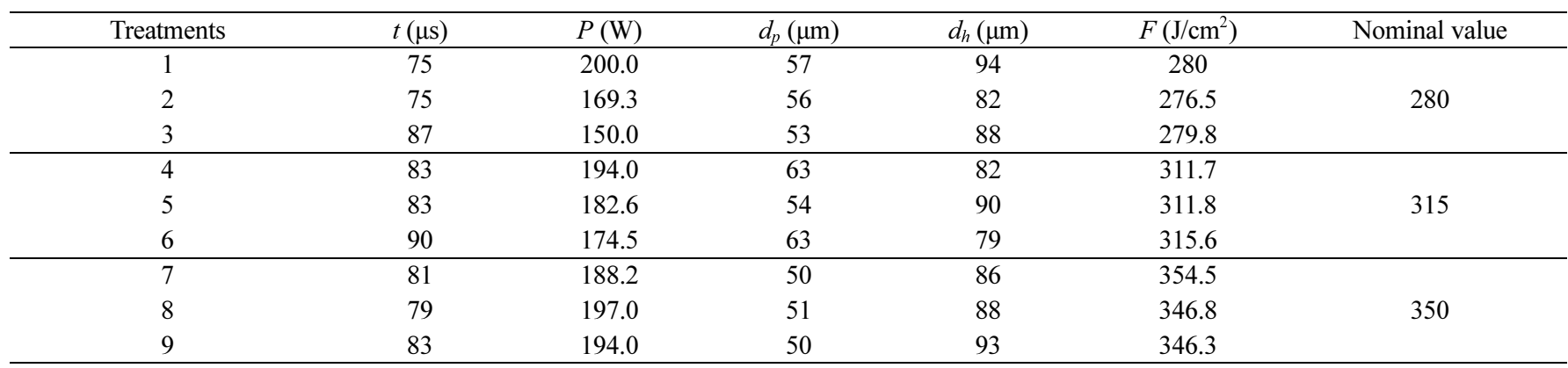

a continuous mode laser. The authors studied a single level of fluence obtained by varying laser power and scan speed; layer thickness and hatch distance were kept constant. Laser power was varied between 40 W up to $320 \mathrm{~W}$, while scan speed from $182 \mathrm{~mm} / \mathrm{s}$ up to $1455 \mathrm{~mm} / \mathrm{s}$.

As in the work by $\mathrm{Gu}$ et al.,22 the values of the process parameters chosen for the experimentation were extreme, e.g., maximum scan speed is eight times its minimum value, the same holds for power. As a result, fluence could not be considered as a unique predictor of tensile properties and density. Scipioni Bertoli et al. ${ }^{24}$ studied six different combinations of process parameters for AISI 316L, resulting in six different fluence values (from $48 \mathrm{~J} / \mathrm{mm}^{3}$ to $242 \mathrm{~J} / \mathrm{mm}^{3}$ ). Six different power values were used (from $100 \mathrm{~W}$ to $500 \mathrm{~W}$ ) and laser speed was changed accordingly to obtain the desired fluence values. The authors studied the melt track geometry (width, height) versus the volumetric energy density used. They found that track width increased linearly with fluence, while track height showed a slow decrease. The authors concluded that volumetric fluence could be used to describe the track evolution. However, the experimentation was only limited to melt tracks and no specimen for density or tensile property measurements were produced. In Table 1 a summary of the discussed three papers is reported.

These papers show the interest for a deeper understanding of the densification process in PBF processes. However, they do not address the issue of the behavior of the process in the steady region when considering the same fluence obtained with different parameters combinations. Moreover, these works considered only laser working in continuous mode. In this study, an industrial machine equipped with a pulsed wave laser has been investigated.

Further studies are needed to evaluate if the aggregate index fluence can completely substitute the individual process parameters at least in a steady process region. If it proves that fluence is able to predict the final part density and tensile properties, the choice of the process parameters could be done by applying new objective functions.

For example, given an interval of fluence where mechanical properties are steady, process parameters could be chosen by maximizing the productivity (or material building rate) which is proportional to $d_{p} d_{h} / t$. Moreover, the superior predictive ability of the single aggregate index fluence over the individual process parameters could be used to reduce the experimental effort for future process parameter optimization studies.

The procedure proposed is based on a preliminary evaluation of a steady process region, that is the minimum and the maximum level of fluence to exclude extreme process conditions, which are not useful from a practical point of view. This range has been established by experience based on the results of previous experimentations.

\section{Experimental Setup}

In this work the considered process parameters are:

- Exposure time $t[\mu \mathrm{s}]$, the duration of the laser pulse;

- Power $P[\mathrm{~W}]$, the power emitted by the laser;

- Point distance $d_{p}[\mu \mathrm{m}]$, the distance between consecutive laser spot on the same scan line;

- Hatch distance $d_{h}[\mu \mathrm{m}]$, the distance between consecutive scan lines.

For this experimentation, layer thickness was kept constant at $40 \mu \mathrm{m}$.

\subsection{Process parameters selection}

To find the experimental plan we use the scheme named V-optimal design. ${ }^{25}$ The reason for this choice is twofold. First the scheme is prediction-oriented, i.e. it focuses on the variance of the response prediction estimate which is the aim of this work. Secondly, the minimization of the variance is obtained through the evaluation on a finite (and small) number of points. The first step is the choice of a steady region where density is acceptable. For Maraging steel, this region was estimated from 280 up to $350 \mathrm{~J} / \mathrm{cm}^{2}$. The choice of the steady region is justified by the fact that if the final part density is not achieved, all the other mechanical properties (static and dynamic) are compromised. Therefore, the process conditions must be inside the steady process region and only those conditions are of interest for an industrial use.

The levels of fluence and the process parameter ranges are:

- $\mathrm{F}=\{280,313,350\} \mathrm{J} / \mathrm{cm}^{2}$

- Exposure time $t: 70 \leq t \leq 90 \mu \mathrm{s}$

- Power $P$ : $150 \leq P \leq 200 \mathrm{~W}$ 
- Point distance $d_{p}: 50 \leq d_{p} \leq 70 \mu \mathrm{m}$

- Hatch distance $d_{h}: 75 \leq d_{h} \leq 105 \mu \mathrm{m}$

Each process parameter interval was divided in 20 linear spaced points to create a grid. The spacing between the points allowed to avoid points to be too close to each other.

Considering the above stated range of the process parameters, different combinations of process parameters were generated. In detail, seven combinations of process parameters were considered for each level of fluence of interest. Following the procedure described in Appendix A, only three treatments (out of seven) were chosen to be part of the experimental plan. Eventually, three levels of fluence, each tested with three different treatments, were considered for this study.

The choice of the numbers 7 and 3 are based on two main considerations. The first consideration is computationally based: selecting 3 items out of a set of 7 identifies 35 possible combinations for each fluence level. The total number of combinations evaluated through the procedure for all the fluence levels is equal to $35^{3}=42875$ a reasonable number from a computational point of view.

The second consideration is the number of specimens to produce. A design with 9 different treatments could be replicated three times on the same experimental campaign, i.e. specimens could be produced on the same building platform.

Replicates of the experimental conditions help in understanding the SLM process variability and obtain stronger conclusion on the results. Seventeen control points (reported in Appendix B) were chosen in the region of interest and they were distributed as a $2^{4}$ factorial design with a center point on the grid. The spatial distribution of the control points allowed for the control of the predicted variance all over the region of the parameter window. The treatments chosen are listed in Table 2.

The detailed procedure is described in Appendix A.

\subsection{SLM machine and material characterization}

The material used for the building process is maraging steel $18 \mathrm{Ni} 300$ powder (Sandvik Osprey, Neath, UK). Maraging steel is characterized by high strength and toughness and shows good weldability properties.

Applications for maraging steel parts can be found in the aerospace, tooling and machining industries.

Powder nominal chemical composition is reported in Table 3. Powder morphology was qualitatively analyzed with Zeiss EVO 50 Scanning Electron Microscope. The nominal particle size distribution belongs to the range $15-45 \mu \mathrm{m}$. Particle distribution and SEM images are reported in Fig. 2.

Renishaw AM250 was used throughout the experimental process. The system is equipped with Nd:YAG Laser in Q-switched mode with a maximum power of $200 \mathrm{~W}$. The build platform is made of stainless steel and its dimensions are $250 \mathrm{~mm} \times 250 \mathrm{~mm}$. The process works under argon atmosphere, maintaining the oxygen content below $0.9 \%$.

To enter the process parameters in Magic ${ }^{\circledR}$ Software, the values in Table 1 have been rounded off to the nearest integer, except for power which was rounded to the first decimal value. The specimens were cylindrical tensile test specimens whose geometry was provided by Renishaw. The geometry of tensile specimen and an example of produced part are shown in Fig. 3. Each specimen was designed with a numerical tag on the top surface. All samples were built along the $\mathrm{z}$ direction. Three replicates for each treatment were produced and four
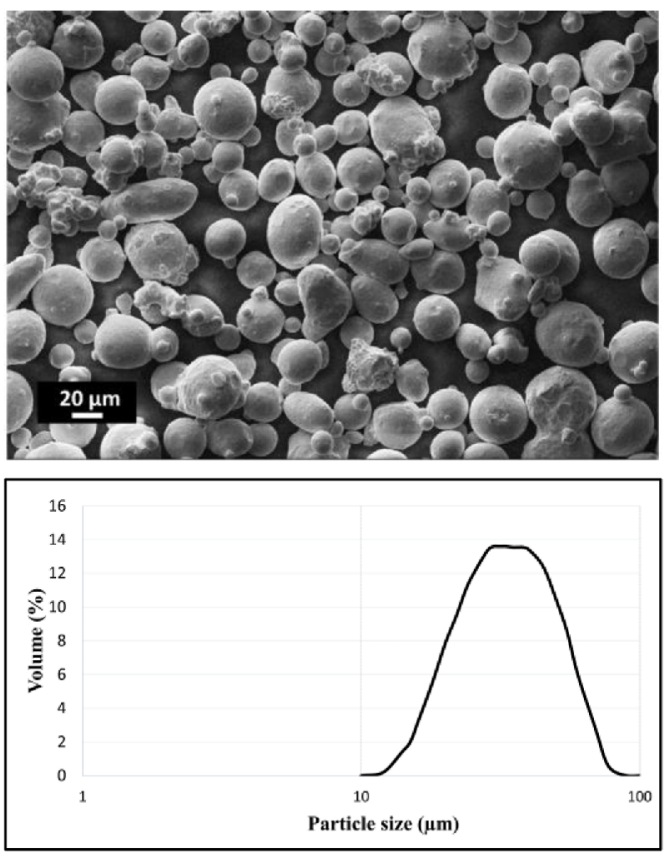

Fig. 2 SEM images of maraging powder and particle size distribution

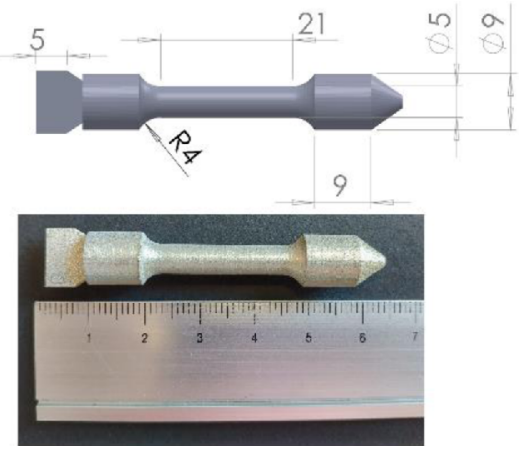

Fig. 3 Geometry of tensile test specimen in $\mathrm{mm}$

Table 3 Nominal chemical composition of Maraging powder

\begin{tabular}{ccccccc}
\hline Powder & $\mathrm{Ni}$ & $\mathrm{C}$ & $\mathrm{Mo}$ & $\mathrm{Ti}$ & $\mathrm{C}$ & $\mathrm{Fe}$ \\
\hline Maraging & $17.6 \%$ & $9.6 \%$ & $5.3 \%$ & $0.7 \%$ & $0.015 \%$ & Balance \\
\hline
\end{tabular}

Table 4 Renishaw suggested parameters for Maraging steel

\begin{tabular}{ccccc}
\hline$t(\mu \mathrm{s})$ & $P(\mathrm{~W})$ & $d_{p}(\mu \mathrm{m})$ & $d_{h}(\mu \mathrm{m})$ & $F\left(\mathrm{~J} / \mathrm{cm}^{2}\right)$ \\
\hline 80 & 200 & 65 & 80 & 308
\end{tabular}

specimens with Renishaw suggested process parameters (in Table 4) were added to the build. Summing up, 40 specimens were produced on the same building plate $(9$ treatments $\times 3$ replicates +4 Renishaw standard process parameters).

\subsection{Density measurement}

Density $\rho\left(\mathrm{g} / \mathrm{cm}^{3}\right)$ is one of the mechanical properties studied in this paper. Different methods are available for density measurement: X-ray computed tomography, micrographs analysis and Archimedes method.

While Archimedes method measured the mean density of the part, $\mathrm{X}$-ray Computed tomography allows to have information on the 
individual characterization of the pores in the component. Spierings et al. ${ }^{26}$ showed that the most accurate and repeatable method for part density measurement is the Archimedes method.

For the measurements, an electronic balance with a Sartorius YDK 01 kit for the density measurement was used.

The calculation of density $\rho$ was made with the following formula:

$$
\rho=\frac{W_{a} \rho_{f l}}{W_{a}-W_{f l}}
$$

where $W_{a}$ is the weight of the specimen in air [g], $W_{f l}$ is the weight of the specimen in water $[\mathrm{g}]$ and $\rho_{f l}$ is the density of the water $\left[\mathrm{g} / \mathrm{cm}^{3}\right]$. During the measurement water temperature, air temperature and air pressure were constantly measured. The measurements were conducted in deionized water and the temperature dependence of $\rho_{f l}$ with the temperature of the water was considered. The measured density of each specimen was compared to $8.1 \mathrm{~g} / \mathrm{cm}^{3}$, which is the expected density of Maraging steel.

\subsection{Tensile measurement}

Tensile tests were performed at room temperature with an initial speed of $0.4 \mathrm{~mm} / \mathrm{min}$ and a secondary speed of $2 \mathrm{~mm} / \mathrm{min}$. The removal point was set at $0.16 \mathrm{~mm}$. The machine used for the tensile test was a MTS Alliance RF/150 (MTS, Eden Prairie, MN, USA). An MTS 632 $26 \mathrm{~F}-20$ extensimeter with a gage length of $8 \mathrm{~mm}$ was used.

\section{Results and Discussion}

In this section the measurement results are discussed.

\subsection{Density measurement results}

Part density varied between 7.99 to $8.05 \mathrm{~g} / \mathrm{cm}^{3}$, which correspond to $98.64 \%$ and $99.38 \%$ of the full density of maraging steel respectively. In Appendix B the table of the results is available. Figs. 4 and 5 show the measurement results. The density in the range $280-350 \mathrm{~J} / \mathrm{cm}^{2}$ is steady, as designed and expected. The improvement in final part density as fluence increases is not significant from a practical point of view. The trend between density and fluence is shown in Fig. 4. Looking at Fig. 5, the individual process parameters appear to have no impact on density. The Renishaw condition is characterized by a high variability, as the range of the measurement is $0.035 \mathrm{~g} / \mathrm{cm}^{3}$. All the samples were randomly located on the building platform, so any location-related effect on the density can be statistically ignored. In general, the repeatability of the replicated conditions is quite good.

The least difference among replicated condition is found for treatment 7 , equal to $0.006 \mathrm{~g} / \mathrm{cm}^{3}$, while the highest range is for treatment 4 , equal to $0.06 \mathrm{~g} / \mathrm{cm}^{3}$.

To validate the thesis of the paper, we have to prove that using the aggregate index fluence is better than using the individual process parameters. To do that, first we fit two empirical models: the first one between the response variable part density and the predictor fluence; the second one among the same response variable and the individual process parameters. Secondly, we must to compare the two models and conclude if our thesis is data supported or not.

The experimental data reported in table B.2 were analyzed with

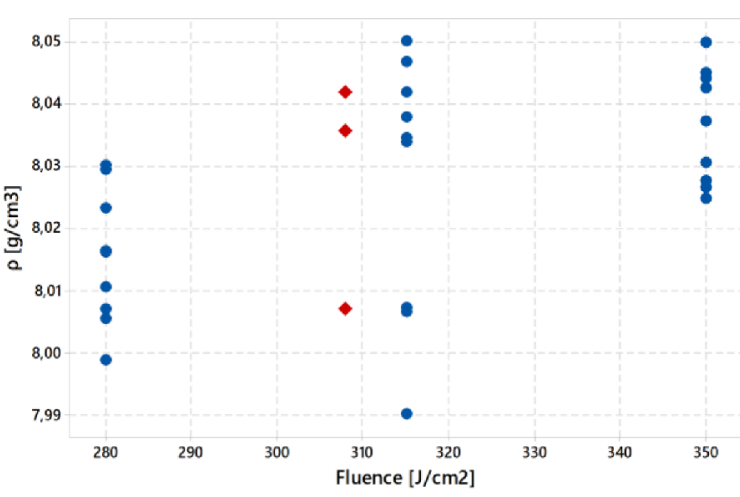

Fig. 4 Scatterplot of Density measurement versus Fluence for Maraging steel. The data related to the Renishaw suggested process conditions are plotted as red diamonds

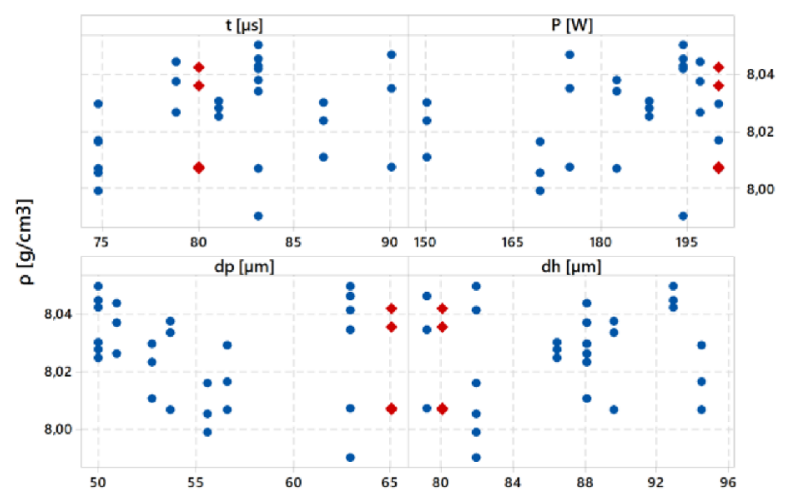

Fig. 5 Scatterplot of Density measurement versus process parameters for Maraging steel. The data related to the Renishaw suggested process conditions are plotted as red diamonds

Minitab ${ }^{\circledR}$ software. The best model for $\hat{\rho}=\hat{\rho}(F)$ is a linear first order model with equation $\hat{\rho}=8.015+0.02256 \cdot F$. The standard deviation of the model is equal to $0.000216 \mathrm{~g}$.

The complete regression table is reported in Table 5. It is evident that the hypothesis of steady process in the considered fluence region is not perfectly proved, but the $\mathrm{F}$ coefficient is negligible for practical purposes. The best model for $\hat{\rho}=\hat{\rho}\left(t, P, d_{p}, d_{h}\right)$ was a linear first order model with equation:

$$
\rho=8.001+0.0301 t+0.0278 P-0.0169 d_{p}-0.0016 d_{h}
$$

The standard deviation of the regression model is $0.000218 \mathrm{~g}$.

The regression table is reported in Table 6. Table 6 shows that the hatch distance and the point distance are not significant, as they have a high p-value $(>0.05)$. The exposure time is significant, while power, if you use a Bonferroni approach, is not significant at $5 \%$ familywise error rate. However, we preferred a full regression model considering all the fluence components. The standard deviation of the two regression models are similar showing a comparable estimation of the error variance. Standard regression assumptions on the residuals of the two regression models are not rejected.

The comparison of the two regression models $\hat{\rho}=\hat{\rho}(F)$ and $\hat{\rho}=\hat{\rho}\left(t, P, d_{p}, d_{h}\right)$ is carried out using confidence intervals, see 
Table 5 Regression table for model $\hat{\rho}=\hat{\rho}(F)$

\begin{tabular}{ccccc}
\hline Source & df & MS & F-value & p-value \\
\hline F & 1 & 0.002011 & 9.25 & 0.005 \\
Error & 29 & 0.000218 & & \\
Lack-of-fit & 8 & 0.000119 & 0.47 & 0.867 \\
Pure Error & 21 & 0.000255 & & \\
\hline Total & 30 & & & \\
\hline
\end{tabular}

Table 6 Regression table for model $\hat{\rho}=\hat{\rho}\left(t, P, d_{p}, d_{h}\right)$

\begin{tabular}{ccccc}
\hline Source & $\mathrm{df}$ & $\mathrm{MS}$ & $\mathrm{F}$-value & $\mathrm{p}$-value \\
\hline Regression & 4 & 0.002654 & 3.05 & 0.0038 \\
$t$ & 1 & 0.001845 & 8.47 & 0.007 \\
$P$ & 1 & 0.001485 & 6.28 & 0.015 \\
$d_{p}$ & 1 & 0.000462 & 2.12 & 0.157 \\
$d_{h}$ & 1 & 0.000004 & 0.02 & 0.899 \\
\hline Error & 26 & 0.005665 & & \\
Lack-of-fit & 5 & 0.000307 & 0.24 & 0.940 \\
Pure Error & 21 & 0.005358 & & \\
\hline Total & & & &
\end{tabular}

Table 7 Average amplitude $\Delta$ and standard deviation of confidence intervals for the model $\hat{\rho}=\hat{\rho}\left(t, P, d_{p}, d_{h}\right)$ and amplitude $\Delta$ for model $\hat{\rho}=\hat{\rho}(F)$

\begin{tabular}{ccc}
\hline $\begin{array}{r}\text { Fluence } \\
{\left[\mathrm{J} / \mathrm{cm}^{2}\right]}\end{array}$ & Mean (St.dev) $\Delta_{C I\left(t, p, d_{p}, d_{h}\right)}\left[\mathrm{g} / \mathrm{cm}^{3}\right]$ & $\Delta_{C I(F)}\left[\mathrm{g} / \mathrm{cm}^{3}\right]$ \\
\hline & $\hat{\rho}=\hat{\rho}\left(t, P, d_{p}, d_{h}\right)$ & $\hat{\rho}=\hat{\rho}(F)$ \\
\hline 290 & $0.0156(0.0053)$ & 0.0072 \\
310 & $0.0141(0.005)$ & 0.0055 \\
330 & $0.0141(0.0045)$ & 0.0064 \\
\hline
\end{tabular}

Appendix A. Confidence intervals (CI) are used to predict the expected response of a regression model for a specified set of predictors. In our case, for the first model the predictor is the fluence, for the second one is the complete set of process parameters $\left(t, P, d_{p}, d_{h}\right)$.

The two regression models can be considered equivalent if their predicted response is statistically the same, which means that the confidence intervals overlap. By analyzing the confidence intervals, two issues are addressed:

- The first one is whether the Confidence Intervals of the two models overlap or not. If they overlap, this would mean that there is no difference in using one model or the other. In other words, that the density of the final part can be predicted with the aggregated index Fluence, at least in the experimental range in which the process is steady or near steady.

- The second issue is the amplitude of the Confidence Interval. The smaller the amplitude of the Confidence Intervals, the higher the precision of the model to predict the response, in our case part density.

To answer the questions previously described, three levels of Fluence, not used in the physical experimentation, were chosen to compare the two regression models: $(290,310,330) \mathrm{J} / \mathrm{cm}^{2}$ and for each level 100 treatments were randomly generated. The fitted regression models discussed were used to evaluate confidence intervals according to the procedure described in Appendix A. In Fig. 6, 100 confidence intervals for 100 combination of process parameters are represented in red and the confidence interval based on the fluence model is represented in

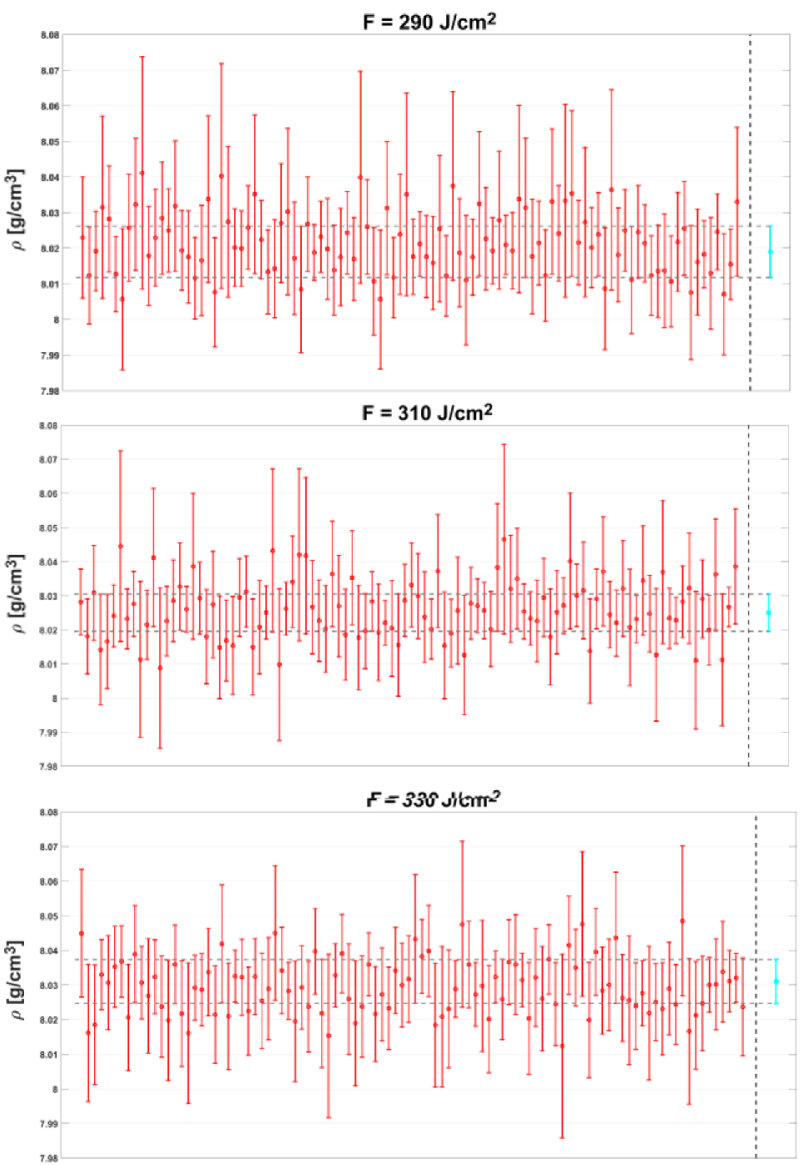

Fig. 6 Confidence intervals for the two models. In red, the confidence intervals for model $\hat{\rho}=\hat{\rho}\left(t, P, d_{p}, d_{h}\right)$ and on the right in light blue the confidence interval for model $\hat{\rho}=\hat{\rho}(F)$

light blue on the far right. For all three fluence levels, the confidence intervals of the two models overlap. This result implies that the two models predict the same density.

The confidence interval based on the model $\hat{\rho}=\hat{\rho}(F)$ shows that its amplitude is lower than the $\hat{\rho}=\hat{\rho}\left(t, P, d_{p}, d_{h}\right)$ (red intervals) ones for each fluence level. The definition of amplitude $\Delta$ of the confidence interval is reported in Appendix A.

Regarding the amplitude of the CI, the average amplitude for both models and the standard deviation of $\Delta_{C I\left(t, p, d_{p}, d_{h}\right)}$ were evaluated and the results are reported in Table 7. As it was also clear from Fig. 6, $\Delta_{C I(F)}$ is almost $50 \%$ smaller than $\Delta_{C I\left(t, p, d_{p}, d_{h}\right)}$.

Using fluence as a predictor, rather than the four process parameters, allowed to reduce drastically the uncertainty of the prediction.

Therefore, fluence can be considered a valuable aggregated index to describe the density of an additive manufactured part when the process parameters used and the fluence interval belong to the steady process region.

\subsection{Static properties}

In this paragraph, we consider the tensile properties to see if the results described in 4.1 are confirmed.

The measured tensile properties for Maraging steel are listed in Table B2 and summarized in Table 8 . In Table 8 the standard deviation 
Table 8 Tensile test results for maraging steel

\begin{tabular}{ccccc}
\hline \multirow{2}{*}{ Treatments } & \multicolumn{2}{c}{ UTS [MPa] } & \multicolumn{2}{c}{ Yield Strength [MPa] } \\
\cline { 2 - 5 } & Mean & StDev & Mean & StDev \\
\hline 1 & 1145.0 & 15.9 & 992.0 & 17.5 \\
2 & 1129.3 & 9.61 & 941.3 & 64.1 \\
3 & 1153.7 & 24.1 & 1002.3 & 75.4 \\
4 & 1138.0 & 39.0 & 977.7 & 20.2 \\
5 & 1156.7 & 21.5 & 1030.3 & 15.3 \\
6 & 1134.0 & 15.6 & 947.0 & 35.1 \\
7 & 1152.0 & 2.00 & 993.7 & 44.6 \\
8 & 1159.0 & 10.1 & 965.3 & 33.9 \\
9 & 1157.7 & 7.37 & 991.3 & 122.9 \\
\hline Renishaw & 1133.3 & 22.6 & 978.5 & 21.9 \\
\hline
\end{tabular}
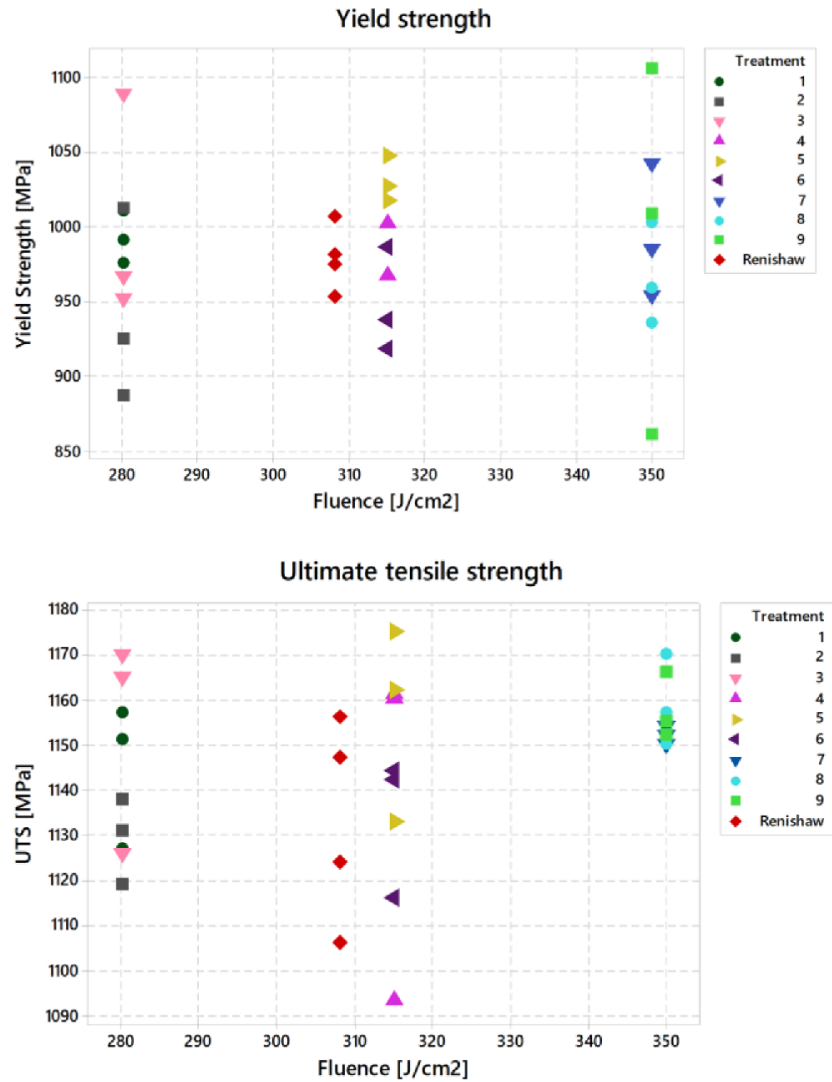

Fig. 7 Tensile properties for maraging steel. Red diamonds refer to Renishaw parameters

is evaluated on the three replicated samples for each treatment. The trend between tensile properties and fluence is shown in Fig. 7.

The overall mean for UTS is $1145.5 \pm 19.8 \mathrm{MPa}$ and for YS is 982 $\pm 51.8 \mathrm{MPa}$. Comparable results were obtained by Yasa et al. ${ }^{27}$ and Suryawanshi et al.. ${ }^{28}$

Yasa et al. ${ }^{27}$ used a Concept Laser M3 Linear SLM Machine equipped with a continuous Nd:Yag laser. They reported results of four samples produced with the same processing conditions; in detail they obtained a UTS of $1290 \pm 112.20 \mathrm{MPa}$ for as-built maraging steel. There was not available information on the Yield Strength. Suryawanshi et al. ${ }^{28}$ produced tensile test specimen with a Concept laser M2, equipped with a fiber laser. Five tensile samples were built with processing conditions resulting in a Fluence of $285 \mathrm{~J} / \mathrm{cm}^{2}$. The results were $825.9 \pm 96 \mathrm{MPa}$

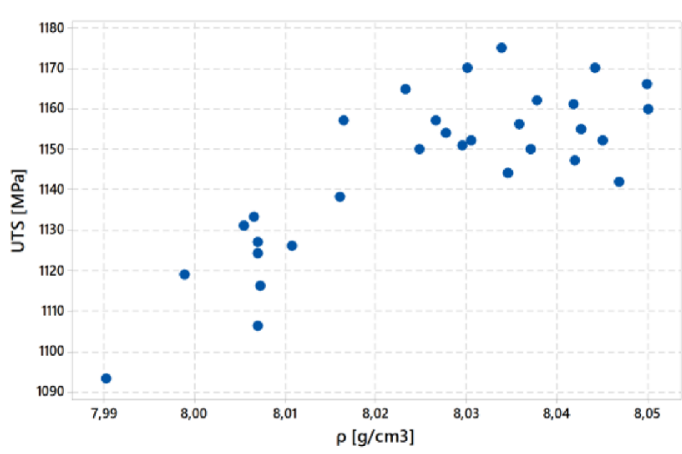

Fig. 8 Scatterplot between tensile properties and density

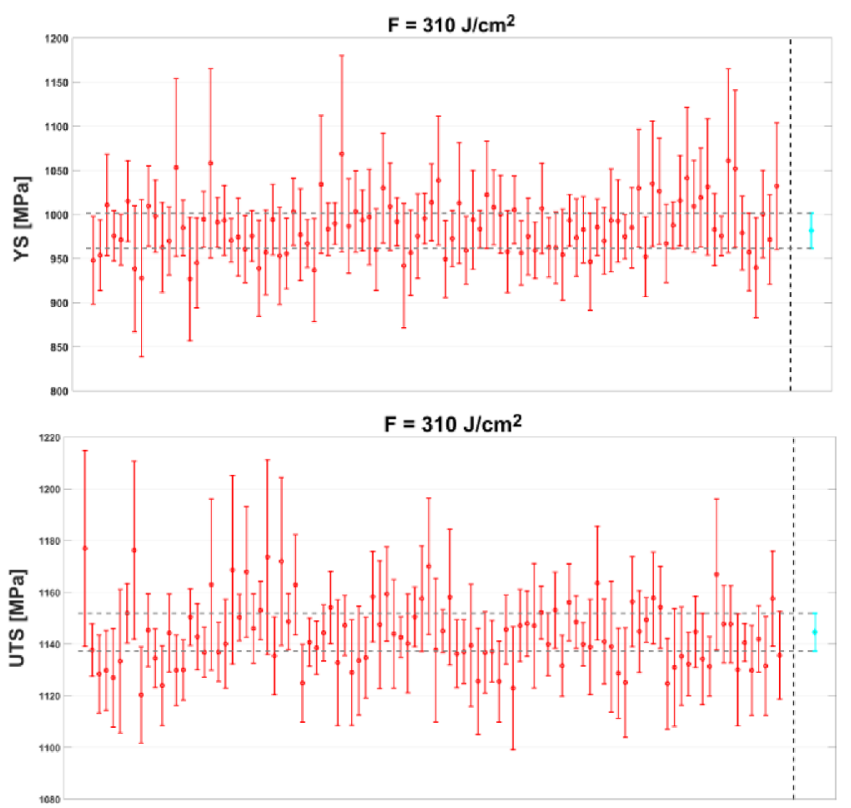

Fig. 9 Confidence intervals for UTS and YS for fluence level $310 \mathrm{~J} /$ $\mathrm{cm}^{2}$. In red, the confidence intervals for the model with the process parameters. The confidence interval for model using fluence is plotted in light blue on the far right

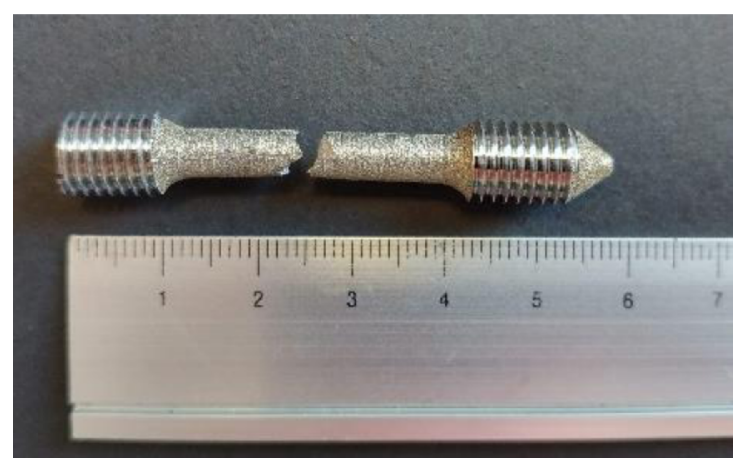

Fig. 10 Image of tensile test specimen after failure

for yield strength and $1324.7 \pm 51 \mathrm{MPa}$ for ultimate tensile strength. In Table 9, tensile properties for maraging steel from literature are compared with the result of the present experimental campaign. In the work by Suryawanshi et al. ${ }^{28}$ samples produced at $285 \mathrm{~J} / \mathrm{cm}^{2}$ are characterized 
Table 9 Comparison of mechanical properties of maraging steel

\begin{tabular}{|c|c|c|c|c|}
\hline Reference & Laser & Fluence / parameters & UTS [MPa] & $\mathrm{YS}$ [MPa] \\
\hline Yasa et al. ${ }^{27}$ & Continuous & $\begin{array}{c}\text { speed }=200 \mathrm{~mm} / \mathrm{s} \\
\text { laser power }=105 \mathrm{~W}\end{array}$ & $\begin{array}{c}1290 \pm 112.20 \\
( \pm 95 \text { confidence interval })\end{array}$ & - \\
\hline Suryawanshi et al. $^{28}$ & Continuous & $\begin{array}{l}285 \mathrm{~J} / \mathrm{cm}^{2} \\
280 \mathrm{~J} / \mathrm{cm}^{2}\end{array}$ & $\begin{array}{c}1324 \pm 51 \\
1142.7 \pm 18.6\end{array}$ & $\begin{array}{c}852 \pm 96 \\
978.6 \pm 57.6\end{array}$ \\
\hline Present work & Pulsed & $\begin{array}{l}315 \mathrm{~J} / \mathrm{cm}^{2} \\
350 \mathrm{~J} / \mathrm{cm}^{2}\end{array}$ & $\begin{array}{c}1142.9 \pm 25.8 \\
1156.2 \pm 7.1\end{array}$ & $\begin{array}{l}985.0 \pm 42.4 \\
983.4 \pm 68.9\end{array}$ \\
\hline
\end{tabular}
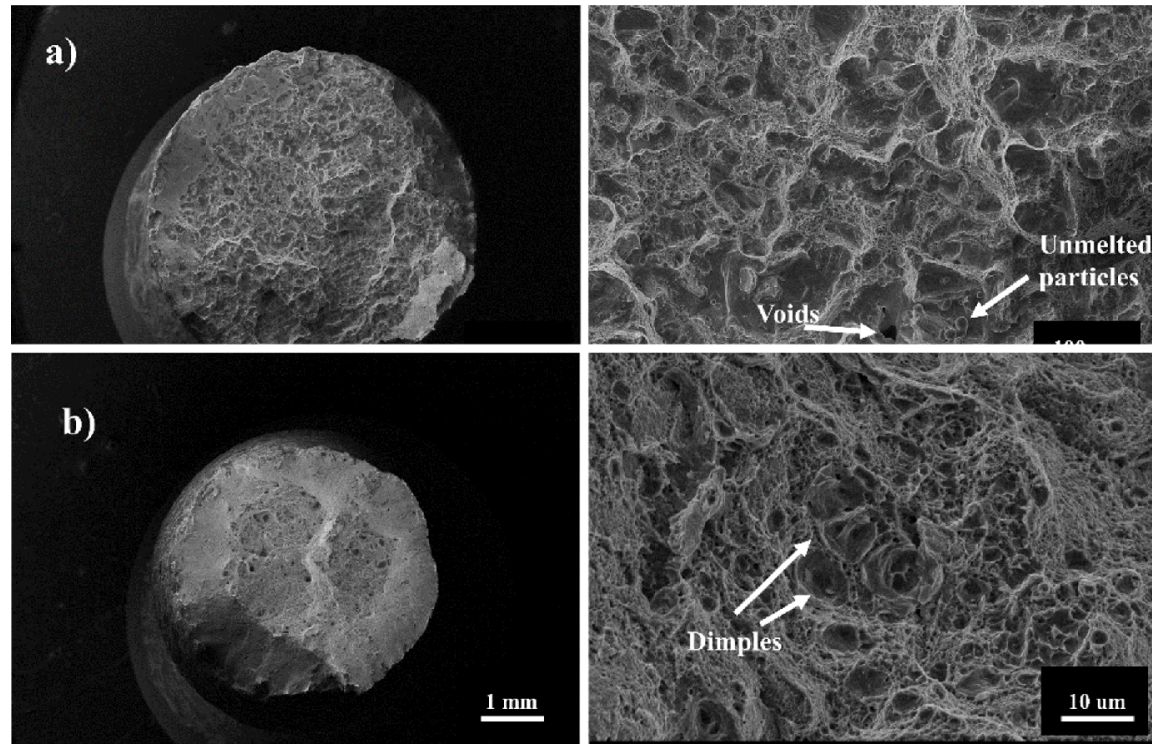

Fig. 11 SEM images of fracture surfaces. a) Sample produced with treatment 2. b) Sample produced with treatment 8

by a variability in YS which is half of the variability in UTS. In the present work, samples produced with fluence $350 \mathrm{~J} / \mathrm{cm}^{2}$ showed a high variability for YS and a small variability for UTS, the same trend was obtained for the other samples (Table 9). Qualitatively the same pattern of small variability in UTS and large variability in YS is obtained in our study and in the work by Suryawanshi et al. ${ }^{28}$

The tensile tests results show that the same range of fluence which allowed a high density, have optimal tensile properties. As it was expected, a high correlation between UTS and density was found, the linear correlation coefficient of Pearson is equal to 0.81 . In Fig. 8, the scatterplot between UTS and density is shown.

In conclusion, a steady process region where both density and tensile properties are maximized exist. Moreover, in this region the influence of the individual process parameters is negligible.

Regression models and confidence intervals for tensile properties were evaluated, according to the procedure described in Appendix A. The same method used for density in Section 4.1 was also applied for tensile properties. As shown in Fig. 8, density and tensile properties are highly correlated, therefore the same results are expected.

As a matter of fact, for both UTS and yield strength regression models were evaluated. One model considering fluence and the second model considering process parameters. The results in terms of confidence intervals are shown in Fig. 9. Only one level of fluence $\left(310 \mathrm{~J} / \mathrm{cm}^{2}\right)$ is displayed for both tensile properties, as the results are the same for all the three levels. Also, for the tensile properties, the predictive ability of the parameters and fluence is the same. All the randomly generated confidence intervals in red overlap the blue interval. Moreover, the interval based on fluence is smaller compared to the interval based on the model considering individual parameters. In conclusion, fluence can be used as an index to predict not only density but also tensile properties.

Scanning electron microscope was also used to examine fracture surfaces of selected tensile test specimen. An example of a specimen after tensile test failure is shown in Fig. 10, while fractographic images are shown in Fig. 11. In Fig. 11(a) tensile specimen produced with treatment 2, whose mechanical properties are density $7.999 \mathrm{~g} / \mathrm{cm}^{3}$, UTS $1119 \mathrm{MPa}$ and YS $1012 \mathrm{MPa}$. The fracture surface is characterized by a dimple-like structure, denoting a ductile fracture. On the surface small porosity and un-melted particles were also observed. In Fig. 11(b) sample produced with treatment 8 is shown; its mechanical properties are density $8.042 \mathrm{~g} / \mathrm{cm}^{3}$, UTS $1170 \mathrm{MPa}$ and YS $959 \mathrm{MPa}$. In this case, the outer perimeter of the sample presents a shear lip surface. The specimen failed after extensive plastic deformation and large dimples dominate the fracture surface.

\subsection{Process optimization}

In the previous analysis we have proven that, at least in a steady process region, fluence is a good aggregate predictor which capture all the process characteristics. Moreover, it was verified that fluence assures an elevated prediction precision for mechanical properties, whatever the individual process parameters are. The knowledge of this region could be used not only for scientific conditions investigation, perhaps to understand the densification mechanism of the material, but also to 


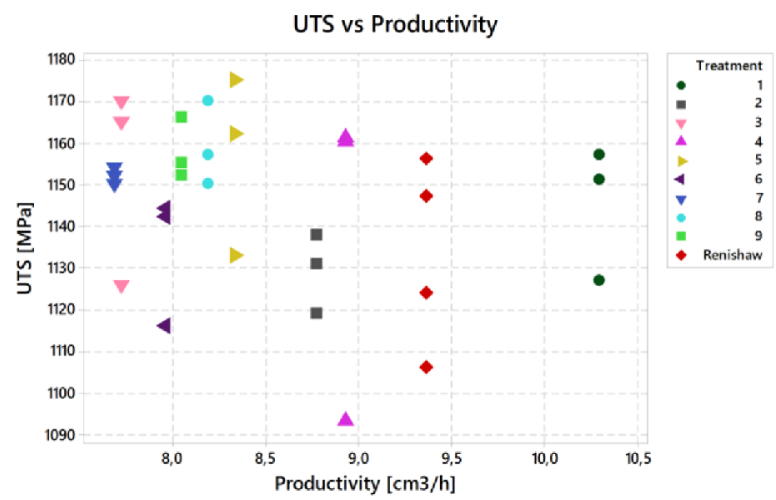

Fig. 12 Tensile properties of Maraging steel at different productivity

choose the optimal process parameters from an industrial point of view.

Usually, parts are built using the parameters suggested by the machine manufacturer for the specific material. However, this choice is not always the most convenient. For example, in this study both density and tensile properties of the treatments were comparable to the Renishaw suggested parameters. The choice of the optimal building parameters could be achieved by considering new goals, such as the maximization of the productivity. In Fig. 12, UTS vs productivity $\left[\mathrm{cm}^{3} / \mathrm{h}\right]$ is shown.

Let us consider that the machine productivity is proportional to $d_{p} d_{h} z$ / $t$. In our case, the layer thickness is kept constant $z=40 \mu \mathrm{m}$. Renishaw suggested conditions are characterized by a high productivity, however treatment 1 ranks first as it exhibits an increased productivity of almost $10 \%$.

\section{Conclusions}

In this paper we investigated the importance of fluence to describe, as a unique factor, the mechanical properties in a SLM process instead of considering the single process parameters. To prove this result, an experimental campaign has been designed using a V-Optimal design (see APPENDIX A) and run. density and tensile properties were measured and analyzed.

The obtained results can be summarized as follows:

- A well-defined procedure has been described and applied to study the influence of fluence and the individual process parameters on SLM parts, using a pulsed laser; as far as we know, for the first time the use of V-optimal design has been used to design this kind of experiment.

- The experimental campaign shows that the predictive ability of the two fitted models are comparable: all the confidence intervals overlap. However, the confidence intervals for the model $\hat{\rho}=\hat{\rho}\left(t, P, d_{p}, d_{h}\right)$ are larger than the ones obtained with the model $\hat{\rho}=\hat{\rho}(F)$. For this reason, the use of fluence as the unique explanatory variable improve the accuracy of the prediction in a steady process parameter region both for density and for tensile properties.

- At least in this experimentation, the identification of a steady region allows to select the process parameters which maximize the properties such as the process productivity.
Future work will try to understand if these results are confirmed for continuous mode lasers and for different materials. The objective will be to generalize the importance of fluence over individual process parameters for a larger set of materials and AM machines.

Moreover, we intend to improve the formalization of the optimization problem by linking it to the specific characteristics of the industrial machine to use and the product to be manufactured.

Another important topic is the relationship between fluence and other mechanical properties. Most of the existing literature deals with fluence as the key factor driving densification. However, a question might rise about the importance of fluence as a descriptor of other mechanical properties, such as fatigue.

\section{ACKNOWLEDGEMENT}

The study was partially funded by the AMATHO Project-Additive MAnufacturing for Tiltrotor HOusing-under H2020-EU.3.4.5.3.-IADP Fast Rotorcraft, in the frame of the CleanSky2-IA Programme.

Open Access: The article published in this journal is distributed under the terms of the Creative Commons Attribution 4.0 International License (http://creativecommons.org/licenses/by/4.0/), which permits unrestricted use, distribution, and reproduction in any medium, provided you give appropriate credit to the original author(s) and the source, provide a link to the Creative Commons license, andindicate if changes were made.

\section{REFERENCES}

1. Herzog, D., Seyda, V., Wycisk, E., and Emmelmann, C., “Additive Manufacturing of Metals," Acta Materialia, Vol. 117, pp. 371-392, 2016.

2. O'Regan, P., Prickett, P., Setchi, R., Hankins, G., and Jones, N., "Metal based Additive Layer Manufacturing: Variations, Correlations and Process Control," Procedia Computer Science, Vol. 96, pp. 216224, 2016.

3. Aboulkhair, N. T., Everitt, N. M., Ashcroft, I., and Tuck, C., "Reducing Porosity in AlSi10Mg Parts Processed by Selective Laser Melting," Additive Manufacturing, Vol. 1, pp. 77-86, 2014.

4. Gong, H., Rafi, K., Starr, T., and Stucker, B., "The Effects of Processing Parameters on Defect Regularity in Ti-6Al-4V Parts Fabricated by Selective Laser Melting and Electron Beam Melting," Proc. of 24th Annual International Solid Freeform Fabrication Symposium - An Additive Manufacturing Conference, pp. 12-14, 2013.

5. Hu, Z., Zhu, H., Zhang, H., and Zeng, X., "Experimental Investigation on Selective Laser Melting of 17-4PH Stainless Steel," Optics and Laser Technology, Vol. 87, pp. 17-25, 2017.

6. Demir, A. G., Colombo, P., and Previtali, B., "From pulsed to 
Continuous Wave Emission in SLM with Contemporary Fiber Laser Sources: Effect of Temporal and Spatial Pulse Overlap in Part Quality," The International Journal of Advanced Manufacturing Technology, Vol. 91, Nos. 5-8, pp. 2701-2714, 2017.

7. Kaden, L., Matthäus, G., Ullsperger, T., Engelhardt, H., Rettenmayr, M., Tünnermann, A., and Nolte, S., "Selective Laser Melting of Copper Using Ultrashort Laser Pulses," Applied Physics A, Vol. 123, No. 9, p. 596, 2017.

8. Maskery, I., Aboulkhair, N. T., Aremu, A. O., Tuck, C. J., Ashcroft, I. A., et al., "A Mechanical Property Evaluation of Graded Density Al-Si10-Mg Lattice Structures Manufactured by Selective Laser Melting," Materials Science and Engineering: A, Vol. 670, pp. 264274, 2016.

9. Zhang, Y., Liu, T., Ren, H., Maskery, I., and Ashcroft, I., "Dynamic Compressive Response of Additively Manufactured AlSi10Mg Alloy Hierarchical Honeycomb Structures," Composite Structures, Vol. 195, pp. 45-59, 2018.

10. Demir, A. G. and Previtali, B., "Additive Manufacturing of Cardiovascular CoCr Stents by Selective Laser Melting," Materials and Design, Vol. 119, pp. 338-350, 2017.

11. Cherry, J. A., Davies, H. M., Mehmood, S., Lavery, N. P., Brown, S. G. R., and Sienz, J., "Investigation into the Effect of Process Parameters on Microstructural and Physical Properties of $316 \mathrm{~L}$ Stainless Steel Parts by Selective Laser Melting," The International Journal of Advanced Manufacturing Technology, Vol. 76, Nos. 5-8, pp. 869-879, 2015.

12. Alfaify, A. Y., Hughes, J., and Ridgway, K., "Critical Evaluation of the Pulsed Selective Laser Melting Process When Fabricating Ti64 Parts Using a Range of Particle Size Distributions," Additive Manufacturing, Vol. 19, pp. 197-204, 2018.

13. Morgan, R., Sutcliffe, C., and O'neill, W., "Density Analysis of Direct Metal Laser Re-Melted 316L Stainless Steel Cubic Primitives," Journal of Materials Science, Vol. 39, No. 4, pp. 1195-1205, 2004.

14. Meier, H. and Haberland, C., "Experimental Studies on Selective Laser Melting of Metallic Parts," Materialwissenschaft und Werkstofftechnik, Vol. 39, No. 9, pp. 665-670, 2008.

15. Simchi, A., "The Role of Particle Size on the Laser Sintering of Iron Powder," Metallurgical and Materials Transactions B, Vol. 35, No. 5, pp. 937-948, 2004.

16. Wang, D., Liu, Y., Yang, Y., and Xiao, D., "Theoretical and Experimental Study on Surface Roughness of 3161 Stainless Steel Metal Parts Obtained through Selective Laser Melting," Rapid Prototyping Journal, Vol. 22, No. 4, pp. 706-716, 2016.

17. Kuo, C., Su, C., and Chiang, A., "Parametric Optimization of Density and Dimensions in Three-Dimensional Printing of Ti-6Al-4V Powders on Titanium Plates Using Selective Laser Melting," International Journal of Precision Engineering and Manufacturing, Vol. 18, No. 11, pp. 1609-1618, 2017.

18. Kobryn, P. A., Moore, E. H., and Semiatin, S. L., "The Effect of
Laser Power and Traverse Speed on Microstructure, Porosity, and Build Height in Laser-Deposited Ti-6Al-4V," Scripta Materialia, Vol. 4, No. 43, pp. 299-305, 2000.

19. Antony, K., Arivazhagan, N., and Senthilkumaran, K., "Numerical and Experimental Investigations on Laser Melting of Stainless Steel 316L Metal Powders," Journal of Manufacturing Processes, Vol. 16, No. 3, pp. 345-355, 2014.

20. Hrabe, N. and Quinn, T., "Effects of Processing on Microstructure and Mechanical Properties of a Titanium Alloy (Ti-6Al-4V) Fabricated Using Electron Beam Melting (EBM), Part 2: Energy Input, Orientation, and Location," Materials Science and Engineering: A, Vol. 573, pp. 271-277, 2013.

21. Spierings, A. B. and Levy, G., "Comparison of Density of Stainless Steel 316L Parts Produced with Selective Laser Melting Using Different Powder Grades," Proc. of the Annual International Solid Freeform Fabrication Symposium, pp. 342-353, 2009.

22. Gu, H., Gong, H., Pal, D., Rafi, K., Starr, T., and Stucker, B., "Influences of Energy Density on Porosity and Microstructure of Selective Laser Melted 17-4PH Stainless Steel," Proc. of 2013 Solid Freeform Fabrication Symposium, 2013.

23. Prashanth, K., Scudino, S., Maity, T., Das, J., and Eckert, J., "Is the Energy Density a Reliable Parameter for Materials Synthesis by Selective Laser Melting?” Materials Research Letters, Vol. 5, No. 6, pp. 386-390, 2017.

24. Bertoli, U. S., Wolfer, A. J., Matthews, M. J., Delplanque, J.-P. R., and Schoenung, J. M., "On the Limitations of Volumetric Energy Density as a Design Parameter for Selective Laser Melting," Materials \& Design, Vol. 113, pp. 331-340, 2017.

25. Montgomery, D. C., "Design and Analysis of Experiments," John Wiley \& Sons, 2017.

26. Spierings, A. B., Schneider, M., and Eggenberger, R., "Comparison of Density Measurement Techniques for Additive Manufactured Metallic Parts," Rapid Prototyping Journal, Vol. 17, No. 5, pp. 380386, 2011.

27. Yasa, E., Kempen, K., Kruth, J., Thijs, L., and Van Humbeeck, J., "Microstructure and Mechanical Properties of Maraging Steel 300 after Selective Laser Melting," Proc. of Solid Freeform Fabrication Symposium, pp. 383-396, 2010.

28. Suryawanshi, J., Prashanth, K., and Ramamurty, U., "Tensile, Fracture, and Fatigue Crack Growth Properties of a 3D Printed Maraging Steel through Selective Laser Melting," Journal of Alloys and Compounds, Vol. 725, pp. 355-364, 2017.

29. Draper, N. R. and Smith, H., “Applied Regression Analysis,” John Wiley \& Sons, 2014.

\section{APPENDIX A}

In this section, we describe the procedure used to select the experimental conditions (treatments). First, we define the optimal 
experimental conditions by means of a type V-alphabetic optimal design, then we discuss the procedure to identify the best model for the generic response variable.

Design of experiments

Let us consider the process parameter Region $\mathbf{p}$ defined as:

$\mathbf{p}:\left\{\mathbf{p} \mid t_{\text {min }}<t<t_{\text {amx }} ; P_{\text {min }}<P<P_{\text {max }} ; d_{p, \min }<d_{p}<d_{p, \max } ; d_{h, \min }<d_{h}<d_{h, \max }\right\}$

where $\mathbf{p}^{T}=\left\{t, d_{p}, d_{h}, \mathrm{P}\right\} \in \mathbf{p}$ is a vector representing the process parameters.

Let us suppose we are interested in a defined set $\mathbf{F}$ of different levels of fluence, $\mathbf{F}=\left\{F_{1}, \ldots, F_{j}, \ldots, F_{N_{F}}\right\}$. For each level of fluence $F_{j}$, the algorithm selects and save all the vectors $\mathbf{p}^{T}=\left\{t, d_{p}, d_{h}, \mathrm{P}\right\}$, which satisfy the constraint:

$$
\begin{gathered}
\ln \left(F_{j}\right)-\varepsilon<\ln P+\ln t-\ln d_{p}-\ln d_{h}<\ln \left(F_{j}\right)+\varepsilon \\
\forall j=1,2, \ldots, N_{F}
\end{gathered}
$$

where $\varepsilon$ is a suitable constant which allows to find the combination of parameters resulting in a fluence level close to $F_{j}$. To solve Eq. (A.2) the process parameter Region $\mathbf{p}$ was divided into a 4-dimensional grid. For each point on the grid, the associated value of fluence was calculated.

If $\varepsilon$ is too small (or zero) it could be possible that no combination of parameters could satisfy Eq. (A.2). On the other hand, if $\varepsilon$ is too large the process parameters satisfying (A.2) could have a fluence too different from $F_{j}$. The procedure, for each level of interest $j$, selects randomly $\boldsymbol{N}_{\boldsymbol{P}}$ process parameters vectors $\mathbf{p}$ satisfying Eq (A.2) and defines the candidate point sets $\mathbf{L}_{j}=\left\{\mathbf{p}_{1 j}, \mathbf{p}_{2 j}, \ldots, \mathbf{p}_{N_{p} j}\right\} \forall j=1,2, \ldots$, $N_{F}$.

For each fluence level, among the candidate points, the algorithm will choose $N_{K}$ specific points with $N_{K}<N_{P}$.

The total number of experiments is $N=N_{K} N_{F}$ if we do not have replicates or $N=n N_{K} N_{F}$ if we have a constant number of replicates $n$.

Note that, in general, we could have a variable number of points for each fluence level, but we restrict the search to a constant number of points to span regularly the process parameter space.

The V-Optimal design scheme works by minimizing the mean prediction variance through a set of previously defined control points. Let us define the set of $\boldsymbol{N}_{\boldsymbol{C}}$ control points C: $\left\{\mathbf{c}_{1}, \mathbf{c}_{2}, \ldots, \mathbf{c}_{N_{c}}\right\}$ with $\mathbf{c} \in \mathbf{p}$. Considering the cuboidal process parameter region, the control points are chosen according to a $2^{4}$ factorial design with a center point. This quite standard choice minimizes the number of points and spans the process parameter region.

Before defining the V-Optimal design scheme, we must assume a model to evaluate the prediction variance.

Let us consider the vector $\mathbf{x}(\mathbf{p})$ depending on the point belonging to the process parameter region $\mathbf{p}$ and the model we want to use.

The vector is built as follows: for example, if the model is additive with a constant, $\mathbf{x}(\mathbf{p})^{T}=\left\{\begin{array}{llll}1 & t & d_{p} & d_{h} P\end{array}\right\}$, otherwise, if the model is quadratic in the process parameters, the form will be $\mathbf{x}(\mathbf{p})^{T}=\left\{1 t d_{p} d_{h}\right.$ $\left.P t^{2} d_{p}^{2} d_{h}^{2} P^{2}\right\}$.

Depending on the specific model, the $\mathbf{x}$ vector will have $(r+1)$ by 1 dimensions, where $r$ is the number of the elements considered in the assumed model.

The design matrix is:

$$
\mathbf{X}=\left\{\begin{array}{c}
\mathbf{x}_{1}^{T} \\
\mathbf{x}_{2}^{T} \\
\cdots \\
\mathbf{x}_{N}^{T}
\end{array}\right\}
$$

The experimental plan, according the V-Optimal design scheme, is the solution of the following optimization problem:

$$
\begin{aligned}
\underset{\mathbf{p}_{k j}}{\operatorname{Min}} & \sum_{l=1, N_{C}} \mathbf{x}_{C, l}^{T}\left(\mathbf{X}^{T} \mathbf{X}\right)^{-1} \mathbf{x}_{C, l} \\
\text { s.t } \quad \mathbf{p}_{k 1} \in \mathrm{L}_{1} \quad k=1,2, \ldots, N_{K} & \text { and } N_{K}<N_{P} \\
& \mathbf{p}_{k 2} \in \mathrm{L}_{2} \quad k=1,2, \ldots, N_{K} \text { and } N_{K}<N_{P} \\
\ldots & \\
& \mathbf{p}_{k N_{F}} \in \mathrm{L}_{N_{F}} \quad k=1,2, \ldots, N_{K} \text { and } N_{K}<N_{P}
\end{aligned}
$$

As a matter of fact, the optimization problem (A.3) minimizes the POE (Propagation of Error) on the control points subject to the constraint that, for each fluence level $(j)$, only $\mathrm{N}_{\mathrm{K}}$ process parameters vectors, out of $\mathrm{N}_{\mathrm{B}}$ are chosen and the solution is a set of $\mathrm{N}_{\mathrm{K}} \mathrm{N}_{\mathrm{F}}$ vectors belonging to the process parameter region.

In our case the problem (A.3) is solved by an enumeration method evaluating, for each fluence value $\mathrm{j}$, the objective function for all the combination of candidate points belonging to the set $\mathbf{L}_{j}$.

To solve the problem (A.3) we need to assume the relationship between the response variable and the process parameters. This is an assumption we must make without knowing the empirical relationship we will find after the experimentation. This is a well-known problem in optimal design.

We approached the problem with a kind of sensitivity analysis. We assumed two competing models (linear and quadratic model) and the solutions of the optimization were denoted, respectively, as $\mathbf{X}_{\text {lin }}^{*}$ and $\mathbf{X}_{\text {quad }}^{*}$.

Then $\mathbf{X}_{\text {lin }}^{*}$ was used to evaluate the objective function, i.e., the predicted variance on the control points, considering a quadratic model.

Likewise, the predicted variance of the optimal design $\mathbf{X}_{\text {quad }}^{*}$ was evaluated considering a linear model.

The solution which ensured the best behavior in terms of predicted variance regardless of the hypothesis on the model was chosen as the optimal design, $\mathbf{X}_{*}$.

The solution of problem (A.3) is an optimal set of process parameters that is used to carry out the experimentation. Specimens are used to study and measure a chosen mechanical property, say $\phi$.

The experimental data are used to evaluate two regression models, $\phi=\phi(F)$ and $\phi=\phi(\mathbf{p})$, using standard techniques and these two models are compared in terms of their prediction ability. The interested reader might refer to Draper and Smith ${ }^{29}$ for Regression model and analysis.

Considering a processing windows coherent with Section 3.1, we define a new set of $N_{L}$ Fluence levels of interest (we do not use the same fluence levels we used to make the experiments and to fit the models), then for each fluence level we find randomly $N_{M}$ points $\mathbf{p}_{m}$ for a total of $\mathrm{N}_{\mathrm{M}} \mathrm{N}_{\mathrm{L}}$ points.

Montgomery (2009) defined the Confidence Interval for a new point as $\hat{\phi}\left(\mathbf{p}_{m l}\right) \pm t_{\alpha / 2}\left(d f_{E}\right) \sqrt{M S_{E} \mathbf{x}_{m l}^{T}\left(\mathbf{X}_{*}^{T} \mathbf{X}_{*}\right)^{-1} \mathbf{x}_{m l}}$ for model $\phi=\phi(\mathbf{p})$. 
where $\mathbf{p}_{m l}$ is the $m$-th point for the $l$-th fluence level, $\mathbf{X}_{*}$ is the design matrix, $d f_{E}$ are the degrees of freedom of the error in the model, and $t_{\alpha / 2}\left(d f_{E}\right)$ is the $\alpha / 2$-quantile of the Student's $t$ distribution and $M S_{E}$ is the mean squared error of the regression model.

For the $N_{L}$ levels of fluence, the confidence interval is:

$$
\hat{\phi}\left(F_{l}\right) \pm t_{\alpha / 2}\left(d f_{E}\right) \sqrt{M S_{E} \mathbf{x}_{l}^{T}\left(\mathbf{X}_{*}^{T} \mathbf{X}_{*}\right)^{-1} \mathbf{x}_{l}} \text { for model } \phi=\phi(F) .
$$

where $\mathbf{x}_{l}=\left(1 F_{l}\right)^{T}$ and $\mathbf{X}_{*}$ is the design matrix.

Therefore, for each Fluence level $l$, we may compute $m$ confidence intervals for model $\hat{\phi}=\hat{\phi}(\mathbf{p})$ and only one for the model $\hat{\phi}=\hat{\phi}(F)$.

Confidence intervals are compared in terms of amplitude and overlapping.

We define the amplitude of the confidence interval $\Delta$ as

$$
\Delta(\mathbf{p})=t_{\alpha / 2}\left(d f_{E}\right) \sqrt{M S_{E} \mathbf{x}^{T}\left(\mathbf{X}_{*}^{T} \mathbf{X}_{*}\right)^{-1} \mathbf{x}}
$$

Where $\Delta$ defines the uncertainty of the prediction around the fitted value $\hat{\phi}(\cdot)$. The larger $\Delta$, the less accurate is the prediction given by the model.

Table B.1 Control points $\mathbf{c}$ for the optimization problem (A.3)

\begin{tabular}{cccc}
\hline$t[\mu \mathrm{s}]$ & $P[\mathrm{~W}]$ & $d_{p}[\mu \mathrm{m}]$ & $d_{h}[\mu \mathrm{m}]$ \\
\hline 75 & 163 & 52 & 83 \\
75 & 188 & 52 & 83 \\
85 & 163 & 52 & 83 \\
85 & 188 & 52 & 83 \\
75 & 163 & 65 & 83 \\
75 & 188 & 65 & 83 \\
85 & 163 & 65 & 83 \\
85 & 188 & 65 & 83 \\
75 & 163 & 52 & 98 \\
75 & 188 & 52 & 98 \\
85 & 163 & 52 & 98 \\
85 & 188 & 52 & 98 \\
75 & 163 & 65 & 98 \\
75 & 188 & 65 & 98 \\
85 & 163 & 65 & 98 \\
85 & 188 & 65 & 98 \\
80 & 175 & 60 & 90 \\
\hline
\end{tabular}

\begin{tabular}{|c|c|c|c|c|c|c|}
\hline $\begin{array}{c}t \\
{[\mu \mathrm{s}]}\end{array}$ & $\begin{array}{c}P \\
{[\mathrm{~W}]}\end{array}$ & $\begin{array}{c}d_{p} \\
{[\mu \mathrm{m}]}\end{array}$ & $\begin{array}{c}d_{h} \\
{[\mu \mathrm{m}]}\end{array}$ & $\begin{array}{c}\rho \\
{\left[\mathrm{g} / \mathrm{cm}^{3}\right]}\end{array}$ & $\begin{array}{c}\text { UTS } \\
{[\mathrm{MPa}]}\end{array}$ & $\begin{array}{c}\mathrm{YS} \\
{[\mathrm{MPa}]}\end{array}$ \\
\hline 75 & 169.3 & 56 & 82 & 8.005 & 1131 & 887 \\
\hline 75 & 169.3 & 56 & 82 & 8.016 & 1138 & 925 \\
\hline 75 & 169.3 & 6 & 82 & 7.999 & 1119 & 1012 \\
\hline 87 & 150 & 53 & 88 & 8.030 & 1170 & 952 \\
\hline 87 & 150 & 53 & 88 & 8.023 & 1165 & 1089 \\
\hline 87 & 150 & 53 & 88 & 8.011 & 1126 & 966 \\
\hline 75 & 200 & 57 & 94 & 8.007 & 1127 & 991 \\
\hline 75 & 200 & 57 & 94 & 8.016 & 1157 & 1010 \\
\hline 75 & 200 & 57 & 94 & 8.030 & 1151 & 975 \\
\hline 80 & 200 & 65 & 80 & 8.007 & 1124 & 974 \\
\hline 80 & 200 & 65 & 80 & 8.007 & 1106 & 953 \\
\hline 80 & 200 & 65 & 80 & 8.036 & 1156 & 1006 \\
\hline 80 & 200 & 65 & 80 & 8.042 & 1147 & 981 \\
\hline 83 & 194 & 63 & 82 & 7.990 & 1093 & 966 \\
\hline 83 & 194 & 63 & 82 & 8.050 & 1160 & 966 \\
\hline 83 & 194 & 63 & 82 & 8.042 & 1161 & 1001 \\
\hline 90 & 174.5 & 63 & 79 & 8.007 & 1116 & 986 \\
\hline 90 & 174.5 & 63 & 79 & 8.035 & 1144 & 918 \\
\hline 90 & 174.5 & 63 & 79 & 8.047 & 1142 & 937 \\
\hline 83 & 182.6 & 54 & 90 & 8.007 & 1133 & 1017 \\
\hline 83 & 182.6 & 54 & 90 & 8.034 & 1175 & 1027 \\
\hline 83 & 182.6 & 54 & 90 & 8.038 & 1162 & 1047 \\
\hline 79 & 197 & 51 & 88 & 8.037 & 1150 & 935 \\
\hline 79 & 197 & 51 & 88 & 8.027 & 1157 & 1002 \\
\hline 79 & 197 & 51 & 88 & 8.044 & 1170 & 959 \\
\hline 83 & 194 & 50 & 93 & 8.043 & 1155 & 1008 \\
\hline 83 & 194 & 50 & 93 & 8.050 & 1166 & 861 \\
\hline 83 & 194 & 50 & 93 & 8.045 & 1152 & 1105 \\
\hline 81 & 188.2 & 50 & 86 & 8.028 & 1154 & 1042 \\
\hline 81 & 188.2 & 50 & 86 & 8.025 & 1150 & 985 \\
\hline 81 & 188.2 & 50 & 86 & 8.031 & 1152 & 954 \\
\hline
\end{tabular}

Table B.2 Experimental data

\section{APPENDIX B}

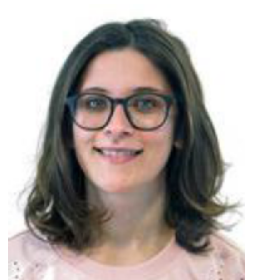

Stefania Cacace

Ph.D. candidate in the Department of Mechanical Engineering, Politecnico di Milano. Her research interest are Additive Manufacturing, design of the experiments and process optimization.

E-mail: stefania.cacace@polimi.it

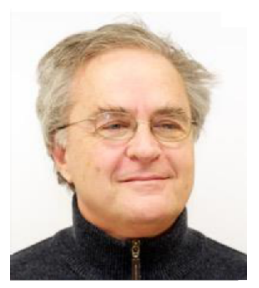

Quirico Semeraro

Professor in the Department of Mechanical Engineering, Politecnico di Milano. His research interest are advanced and traditional machining, industrial statistics, design of the experiments.

E-mail: quirico.semeraro@polimi.it 